\title{
PHOTOGRAMMETRY, LASER SCANNING AND HBIM FOR CONSTRUCTION DIAGNOSTIC
}

\author{
K. Pavelka, jr. ${ }^{1}$, \\ ${ }^{1}$ Department of Geomatics, Faculty of Civil Engineering, CTU in Prague - karel.pavelka@cvut.cz
}

Commission V, WG V/7

KEY WORDS: HBIM, Laser scanning, photogrammetry, minaret.

\begin{abstract}
:
The aim of this article is to show today's possibilities of the documentation of damaged monuments by various technologies on a case study. Laser scanning, mobile laser scanning, terrestrial photogrammetry using hand-held camera, and drone aerial photogrammetry were used. The outputs were textured and non-textured point clouds and an aerial orthophoto of the object. The clouds were compared in terms of possible deformations, the issues of overall accuracy and time required to focus the object were also discussed. The outputs were used for the basic plans of the building, intended for the planned reconstruction and also for the creation of a model for HBIM.
\end{abstract}

\section{INTRODUCTION}

21 st century technologies have changed significantly, and the spatial documentation of the buildings is so detailed that there is talk of a digital twin (Jouan, P., Hallot, P., 2019). The unprecedented development of computer technology and digitization makes it possible to process hundreds of millions of point measurements taken in a relatively short time. Automated close-range photogrammetry ( $\mathrm{SfM}$ ) has developed, and more recently modern laser scanning in the form of TLS (terrestrial laser scanning) and especially PLS (personal laser scanning) (Haala, N., Alshawabkeh, Y., 2006). New technologies and miniaturized instruments allow us to document exactly the desired object in a short time. In terms of restoration of historic objects, it is necessary to create accurate plans and 3D documentation, which is now assumed in the BIM environment (Poloprutský, Z., 2019). The Department of Geomatics at the Faculty of Civil Engineering of the Czech Technical University in Prague has long been involved in the documentation of monuments (Matoušková, E. et al., 2021). It has been involved in projects in Iraqi Kurdistan (Pavelka, k., Pappi, C., Pavelka, k., jr., 2021) since 2006 with the Czech firm Gema Art.

\section{CASE STUDY}

From the example of the restoration of the historic minaret from the current project in Iraq / Kurdistan, it is possible to analyse the possibilities and significant outputs from new technologies. The documented minaret is located in the heart of the Al Qala citadel in Erbil in northern Iraq / Kurdistan (Figure 1); (Housarová, E., Pavelka, K., Šedina, J. 2019), (Pavelka, K., Svatuskova, J., Králová, V. 2007). It is decorated with thousands small glazy bricks; many of them have already fallen away, and certain parts are damaged (Figure 2). The minaret static is unknown, as the structure is visibly deformed. This is an ideal case for the use of contactless documentation methods and the creation of a precise model in the form of a digital twin. Based on the created model, it is possible to analyse the condition, create other suitable outputs and capture the progress of restoration work.

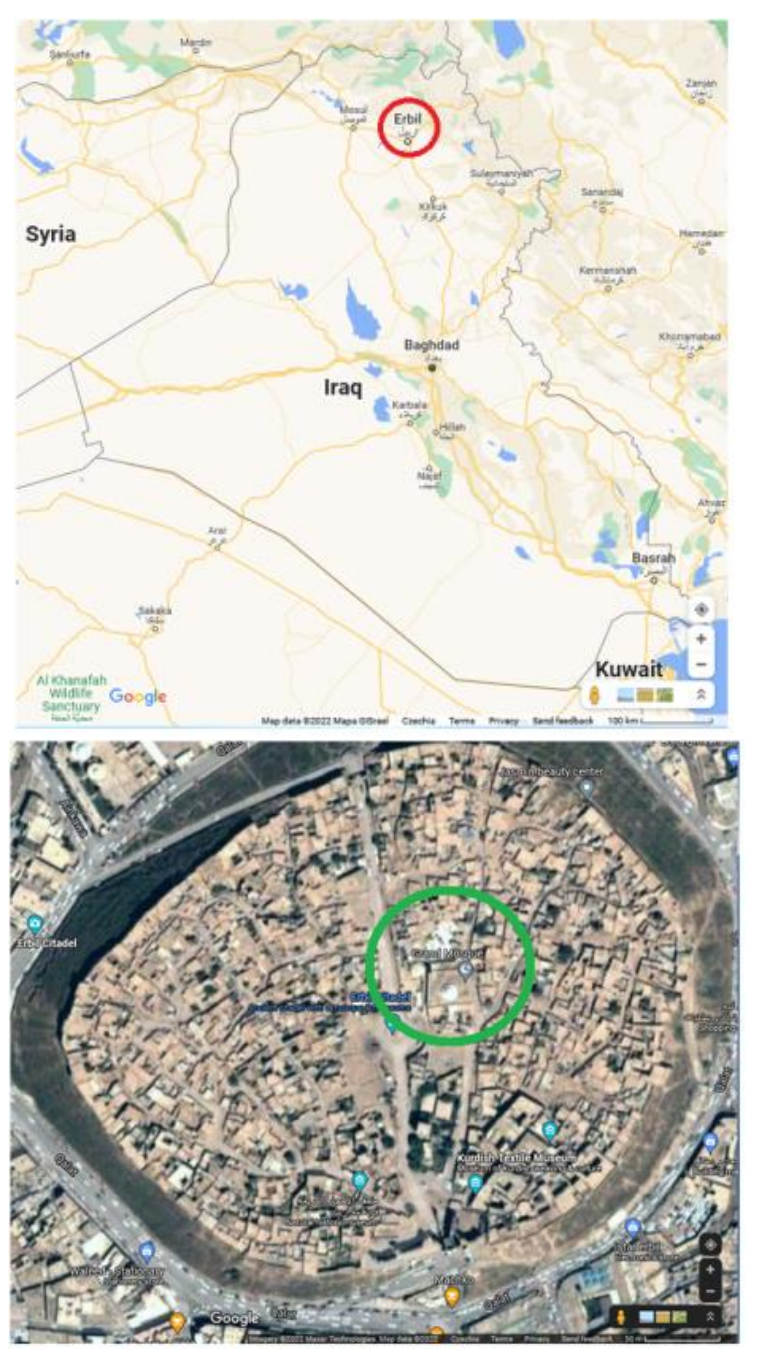

Figure1. Location of the case study, Al-Qala Citadel, Erbil 


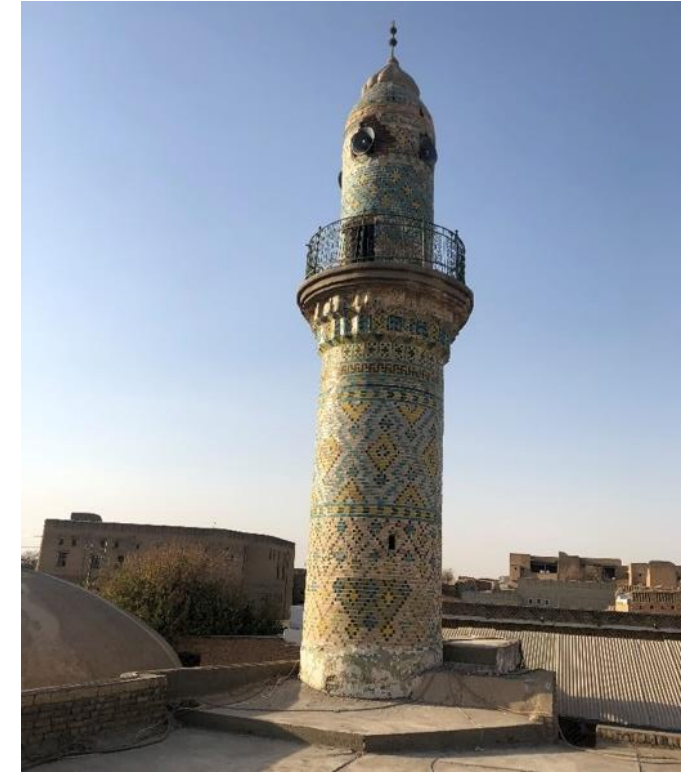

Figure 2. Minaret, citadel Al Qala, Erbil

\section{METHODS AND INSTRUMENTS}

Two basic methods were used for minaret documentation. The first method was a measurement using laser scanners. First, a TLS Leica BLK 360 was used as a reference measurement; 13 scans around the minaret were done. The second measurement was performed by a hand-held PLS ZEB-REVO inside and outside of the minaret. This instrument made measurements inside the minaret and in the wider area (Geoslam, 2022; Leica Geosystems, 2022), Figure 3,4.
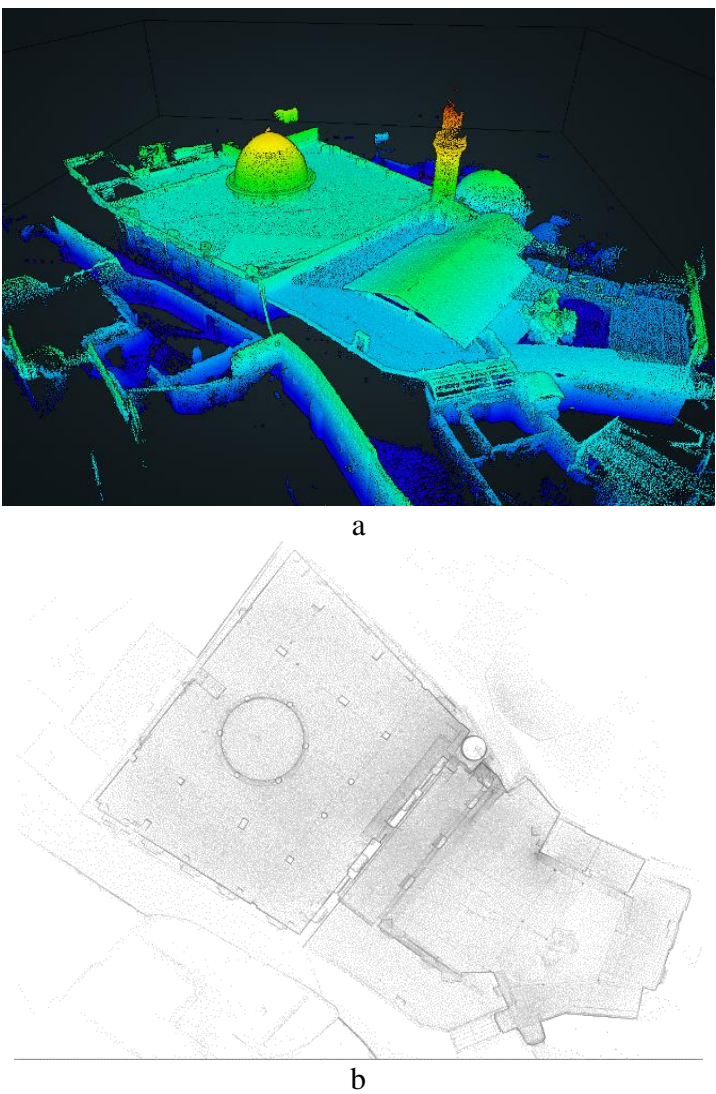

Figure 3. Data from ZEB-REVO; a) point cloud, b) point cloud ortho view serves as a base for vectorising

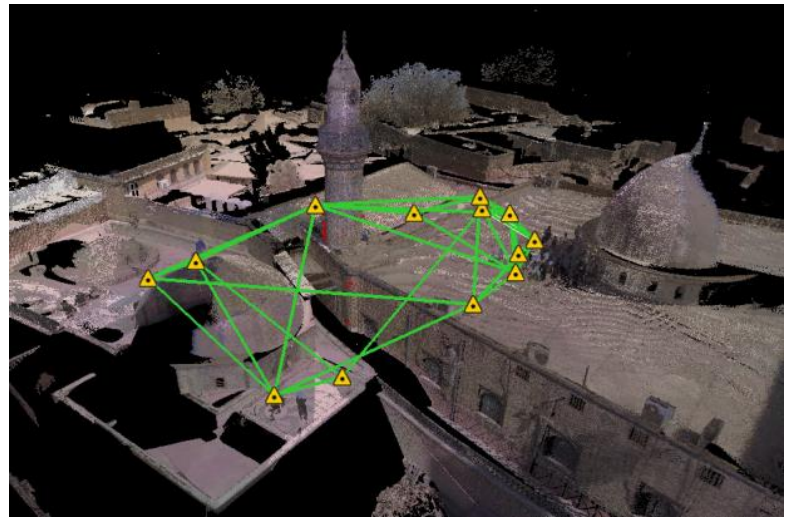

Figure 4. TLS data, 13 positions, bundle error $0.005 \mathrm{~m}$ with overlap $57 \%$, textured point cloud

The last technology used was close-range photogrammetry as a joined measurement with an SLR Canon D450 with $85 \mathrm{~mm}$ lens and DJI Mavic Pro drone. Using the hand-held camera and drone more than 2000 photos were taken from different angles and height. These devices were chosen because they are small, compact, and easy to carry as hand luggage (Hůlková, M. et al., 2016; Patrucco, G. et al., 2019; Šedina, J. et al., 2019), Figure 4.

Creating an accurate model of a tower - in this case a minaret is not easy. It is necessary to combine several technologies due to the height of the building and its accessibility. First, it was necessary to create a perfect $3 \mathrm{D}$ model. It was done using Agisoft Metashape and Reality Capture software. Both use automatic image correlation (SfM-Structure from Motion or in other words IBMR-Image Based Modelling and Rendering) for point cloud generation and joining with laser scanned data. Laser scanned data primarily gets a scale for a photogrammetric 3D point cloud and for an overall deformation check. Generally, real digital photogrammetric data is scale-less, drone data can have a scale based on GNSS instrument. However, low-cost drones like DJI Mavic Pro aren't equipped with RTK GNSS.
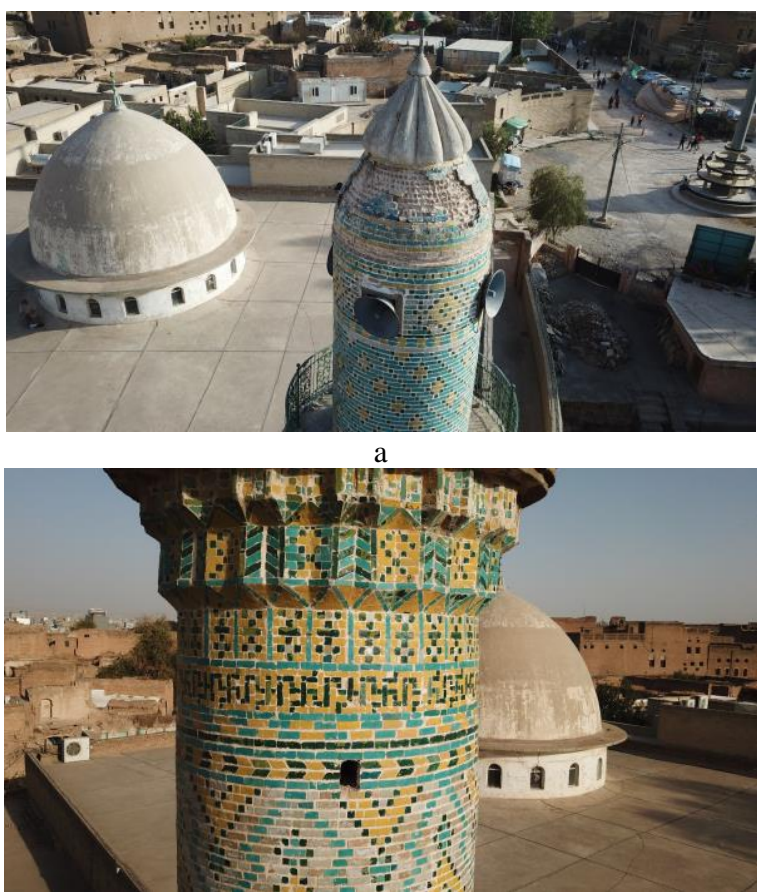

b 


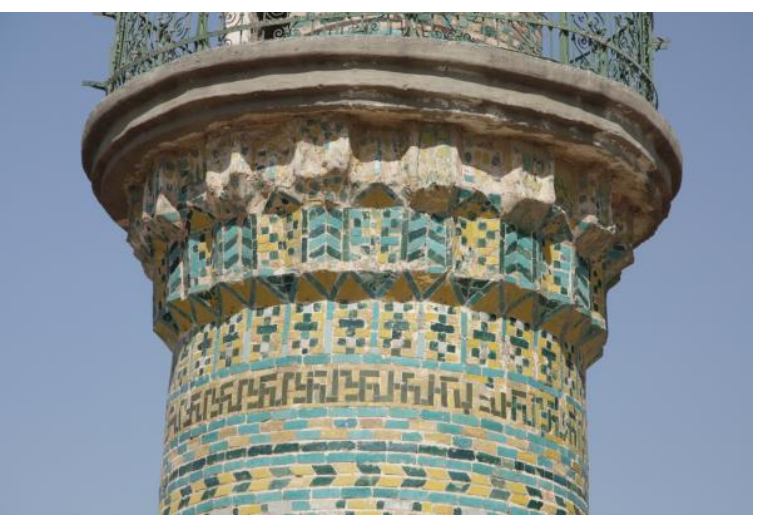

$\mathrm{c}$

Figure 4. a,b) photos from DJI Mavic Pro, c) photo taken by SLR Canon 450 with $85 \mathrm{~mm}$ lens

\section{RESULTS}

The minaret awaits the reconstruction of the facade and stabilization. For these purposes, unrolled photo plans of the decorated minarets tube were created, such as a detailed hiquality $3 \mathrm{D}$ model, cross-sections, and a printed model on a 3D printer. Plans, models, simulations, architectonic and restoration analysis, information stored in a BIM or HBIM, all save the actual condition of minaret and help for future reconstruction. As was written, data was captured using by two different technologies: 1) with aerial and terrestrial photogrammetry, 2) by using of laser scanners (stop and go laser scanner BLK360 and personal mobile laser scanner ZEB-REVO).

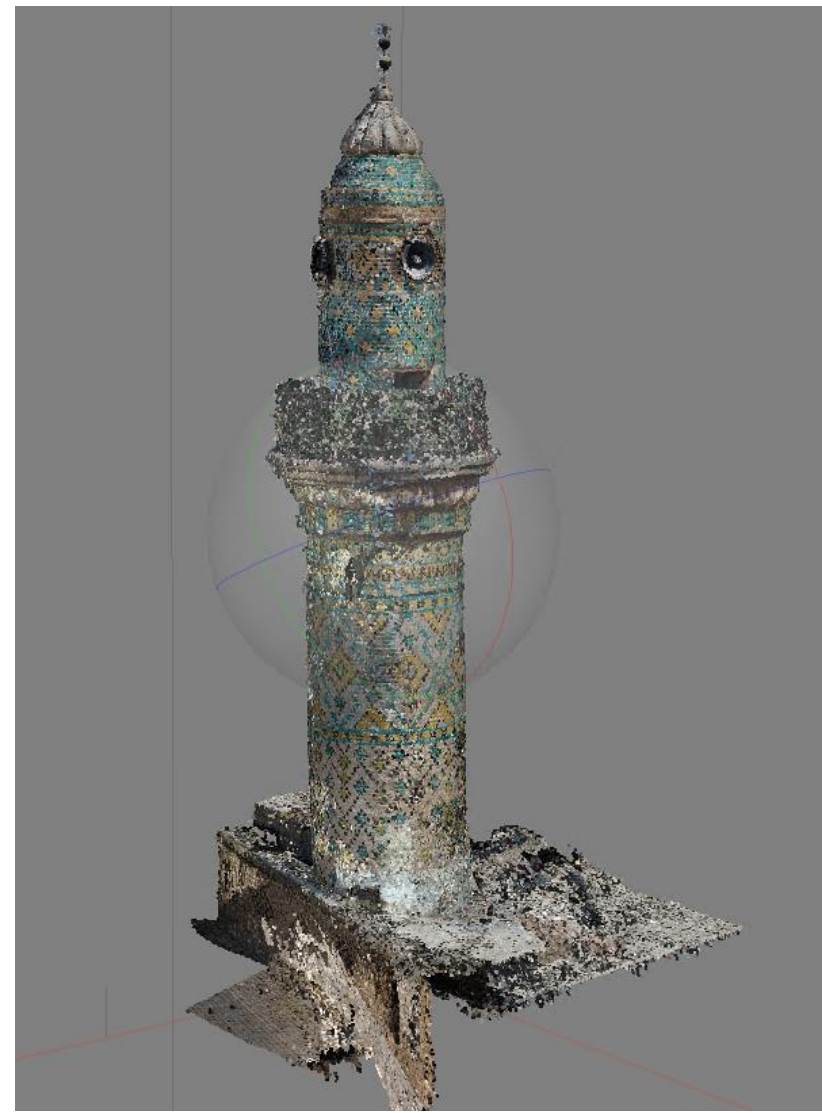

Figure 5. Raw uncleaned point cloud from photogrammetric data in Agisoft Metashape wasn't suitable for precise processing. Until the merging with the laser data yielded very good results.

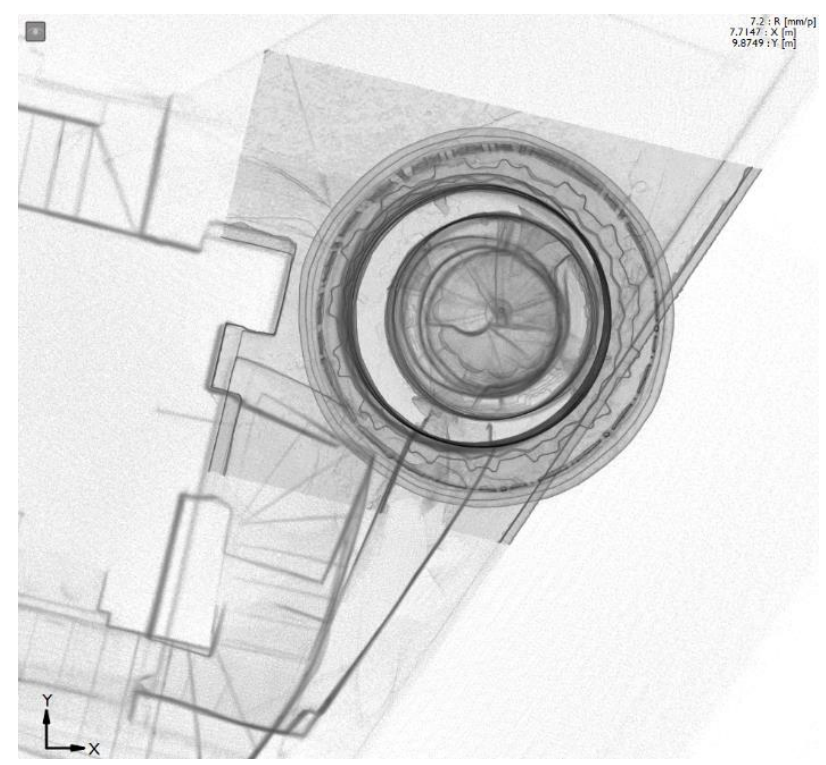

Figure 6. Minaret, ortho-view, a detail of point cloud from PLS ZEB-REVO.

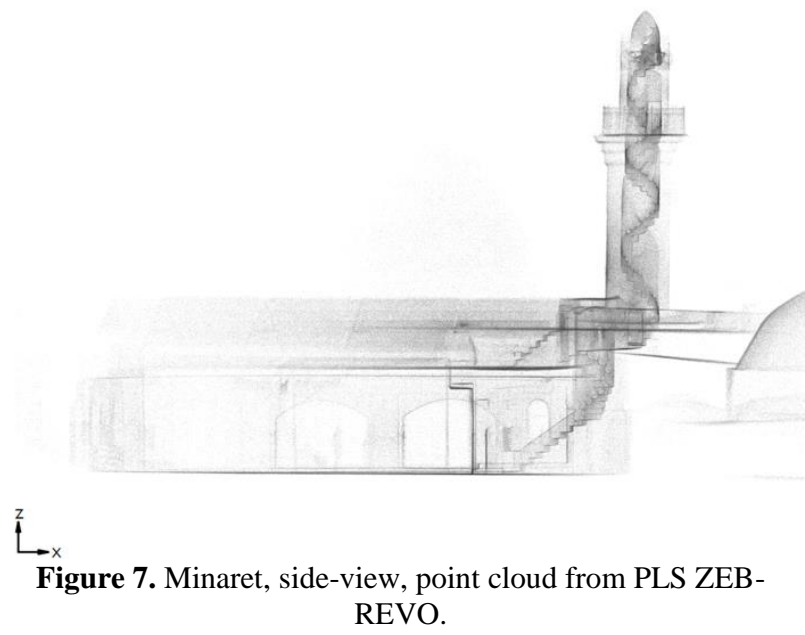

Each technology has some pros and cons and combination of these two methods give precise 3D model for next object analysis.

As was written, data was captured using by two different technologies: 1) with aerial and terrestrial photogrammetry, 2) by using of laser scanners (stop and go laser scanner BLK360 and personal mobile laser scanner ZEB-REVO), Figure 5-7. Each technology has some pros and cons and combination of these two methods give precise 3D model for next object analysis (Erdelyi, J., Kopacik, A., Kyrinovic, P., 2018).

The terrestrial photogrammetry gives us a detailed 3D model, but only from the lower minaret part; due to the shape and minaret height, upper parts cannot be documented using these methods with sufficient quality based on greater distance to the object and oblique angle of view. For this reason, a drone was used to take upper minaret parts with high detail. There is a problem; we did not have a total station for the measuring of precise control points at our disposal. Without control points, the digital photogrammetry is in principle scale-less. A model with an approximately scale gives us only the drone close-range photogrammetry based on in-build GNSS instrument, but in our 
case only a GNSS wits low precision was used (low cost DJI Mavic Pro without RTK system was used). Based on our research, it is possible to process both photo sets (from terrestrial photogrammetry and from drone) to one model only if the angles of view from both systems are not greater than 1525 degrees in the common part and the surface detail is not fundamentally different in size (maximum 1: 3 ); it is also necessary to take connecting pictures, especially from the drone, so that they cover the part photographed by hand.

Both models from both photogrammetric methods can also be processed separately and then combined; however, some software (such as CloudCompare) requires that both models be at least in approximate scale. This needs to be adjusted in advance. In our case, for setting the scale, data from laser scanner BLK360 was used. This scanner has an accuracy of $4 \mathrm{~mm}$ on 10 metres which is sufficient for this purpose. Data from PLS Zeb-Revo was used for creating a vector plan of a broader minarets neighbourhood; this system has an accuracy 1$3 \mathrm{~cm}$ on $10 \mathrm{~m}$ and the point cloud is sparse for precise work; but it is enough for vectorization into a vector plan (Figure 8).

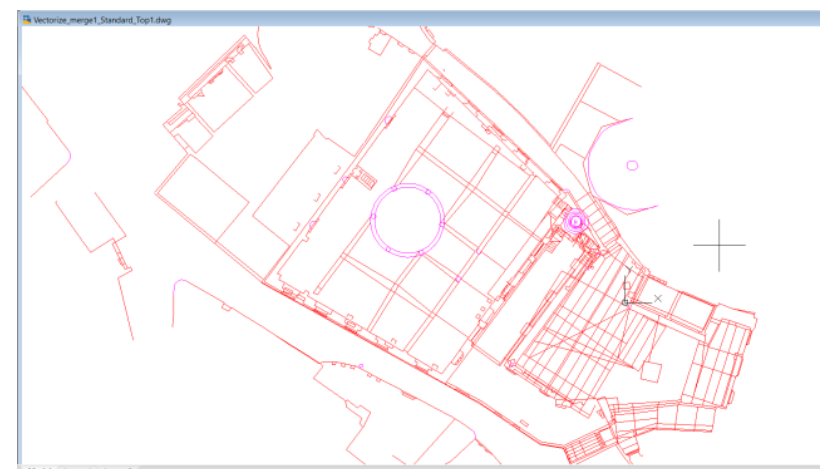

Figure 8. Vector plan created from ZEB-REVO data

The final 3D model of the minaret has around 500,000 polygons with $8192 \times 8192$ texture resolution. The cleaned model and main slitting was done in Geomagic Wrap software. In addition to the 3D documentation of the building, photo-plans of the façade parts were also chosen as one of the outputs. For this reason, the created model was separated into three sections, a bottom part, middle part, and top part. The reason for this separation is easy; it was needed to unroll the 3D model to a photo-plan. Each part has a different diameter, and it is almost impossible to create such a corresponding 2D photo plan of the whole minaret. The created photo-plans (Figure 9,10) were used for restoration purposes.

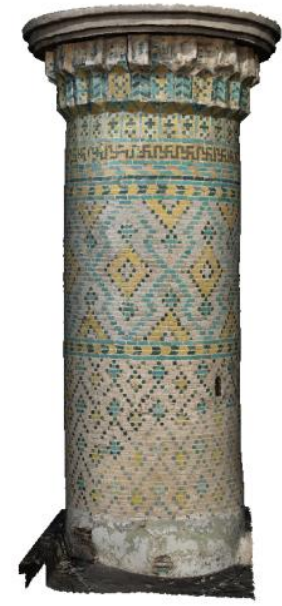

a

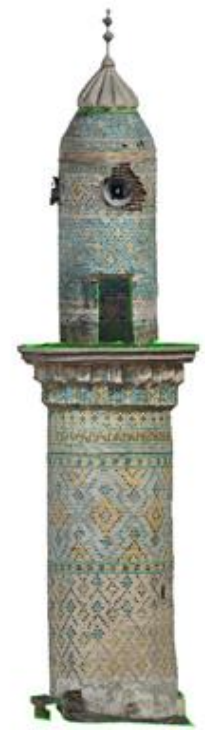

b

Figure 9. a, b) minaret model

For unrolling (Pavelka, K., Ruzicka, S., Bílá, Z., 2013) of the minaret model, CloudCompare software was used. Unfortunately unfolding along poly-lines couldn't be done with mesh, so only work with a point cloud is supported. A 3D model must be converted into the points by the mesh sample point feature. Work in CloudCompare was made with nonreduced models to get the highest possible quality of the facade. For example, bottom part of minaret has about 10,000,000 points. The final facade photo plans have more than $500 \mathrm{MB}$ as a TIF photo per part. The resolution for $\mathrm{A} 0$ reaches a pixel size of $1 \mathrm{~mm}$ (Figure 10-14).
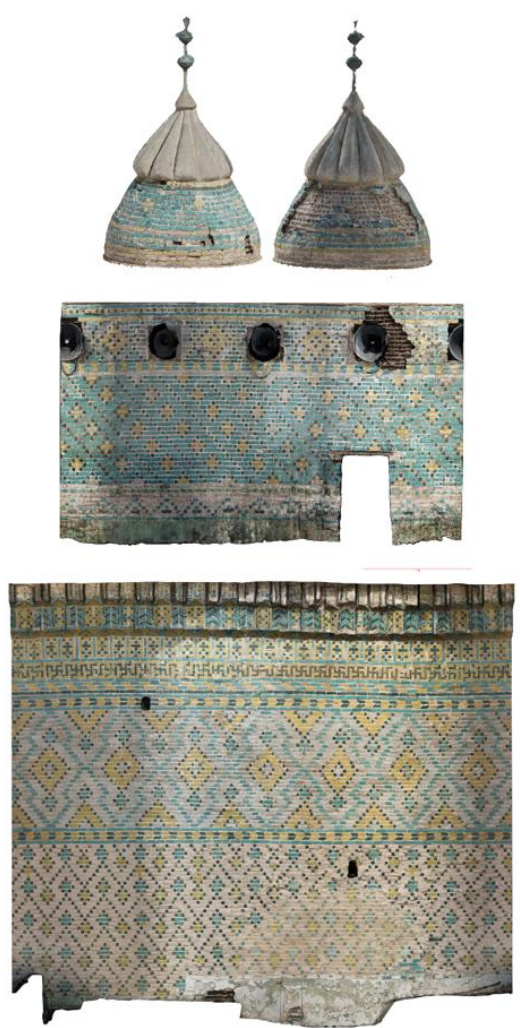

Figure 10. All three photo-plans of the documented minaret parts 


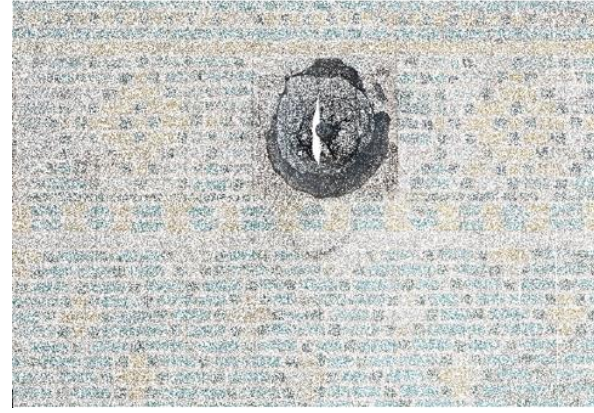

a

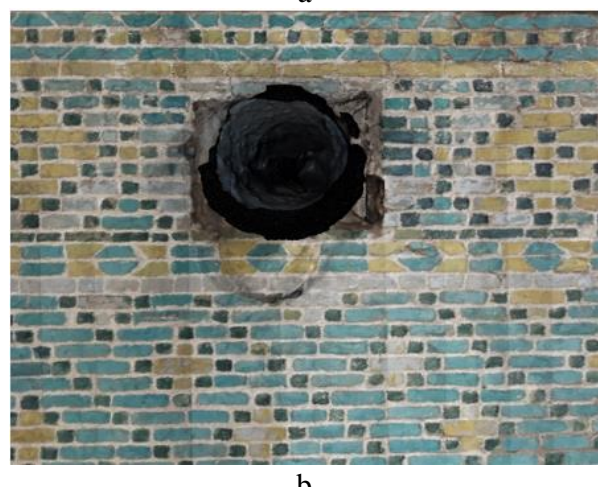

Figure 11. Point cloud a) and b) mesh comparison

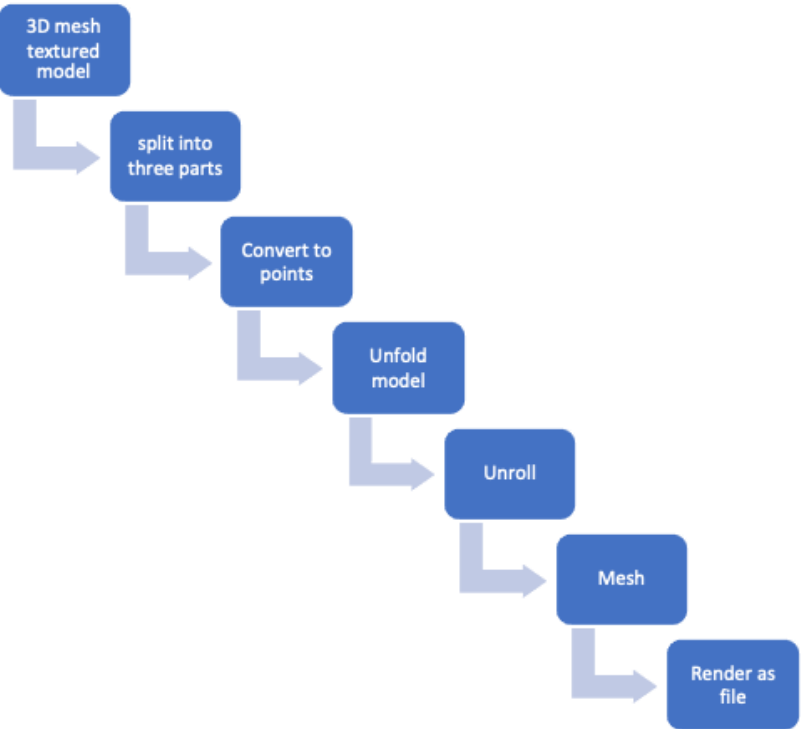

Figure 12. Flowchart of the process used
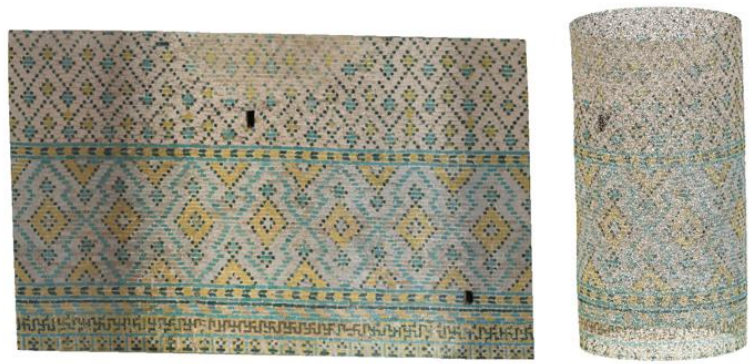

Figure 13. Demonstration of unfolding by polyline

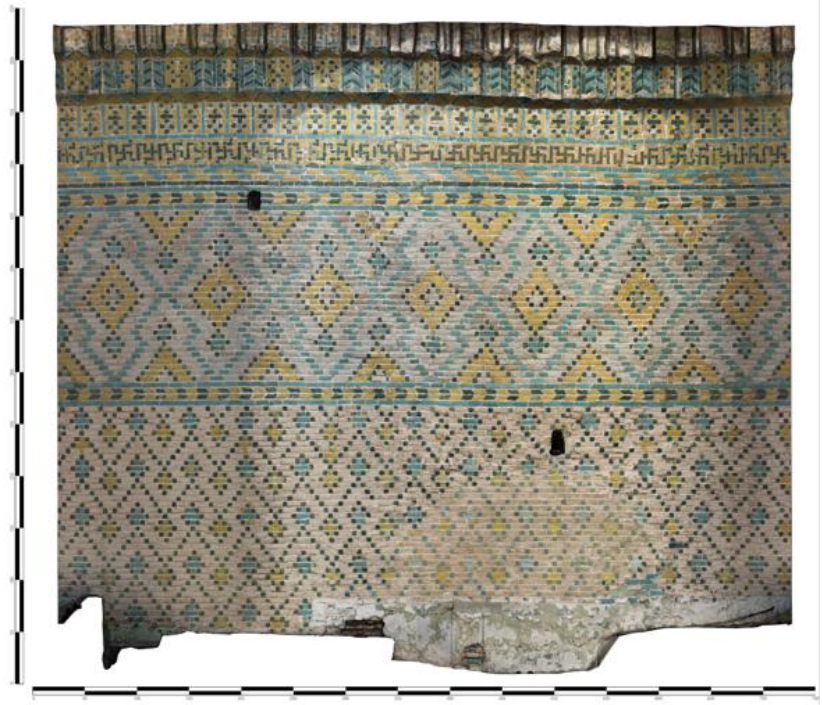

a

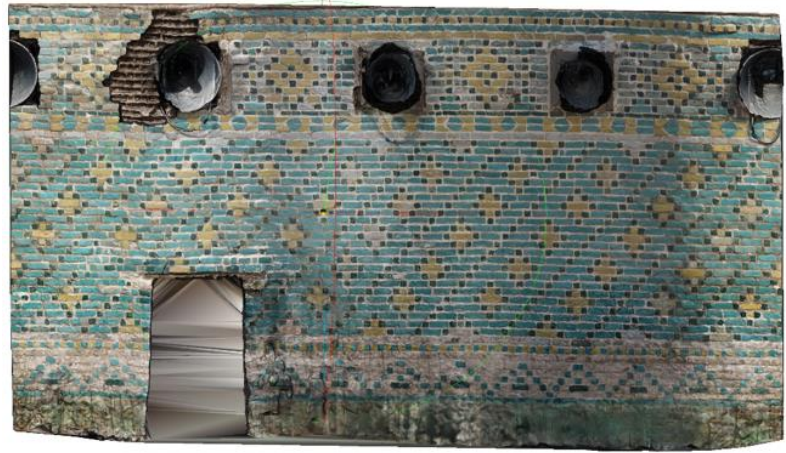

b

Figure 14. a) final un-cleaned mesh, b) final clean model of bottom part

\section{CONCLUSION}

This contribution analyses all of the above-mentioned technologies and methods as primarily input data for BIM/HBIM, describes their suitability, accuracy, as well as advantages and disadvantages. PLS ZEB-REVO was found to be a very fast way to document the wider surroundings and interior of the very narrow minaret and the mosque. Unfortunately, this type does not have a built-in camera, so the output point cloud is without texture and is especially suitable for creating sections and vector plan of the wider environment. The photogrammetric model was created by a combination of terrestrial and aerial close-range photogrammetry using a drone; the scale was delivered from a BLK360 laser scanner. The result was a perfect 3D model of the exterior of the minaret with an important texture. Next, the technology of minaret tube unrolling for the creation of a detailed photo plan was described. All processed outputs were used as a basic material for restoration purposes. Modern technology allows us to create realistic, precise and complex model. Combination of photogrammetry and laser scanning are most used technology for this purpose and give us all data needed for creation of 3D model for all kind of analysis.

\section{ACKNOWLEDGEMENTS}

This project was supported by the CTU grant SGS 2022/k155/Pavelka. 


\section{REFERENCES}

Erdelyi, J; Kopacik, A; Kyrinovic, P. 2018. Construction control and documentation of facade elements using terrestrial laser scanning. Applied geomatics. 2018, 10(2), p.113-121. https://doi.org/10.1007/s12518-018-0208-4

Geoslam, "What is SLAM? 2022. Simultaneous Localization and Mapping," [Online]. Available: https://geoslam.com/whatis-slam/. [Accessed: 06-Jan-2022].

Haala, Norbert \& Alshawabkeh, Yahya. 2006. Combining Laser Scanning and Photogrammetry - A Hybrid Approach for Heritage Documentation. 163-170. https://doi.org/10.2312/VAST/VAST06/163-170

Housarová,E., Pavelka, K., Šedina, J. 2019 Study of Erbil AlQala citadel time changes by comparison of historical and contemporary image data, European Journal of Remote Sensing, 52:sup1, 202-208, DOI: $10.1080 / 22797254.2018 .1531683$

Hůlková, M.; Poloprutský, Z.; Raeva, P.; Matoušková, E.; Housarová, E. 2016. Complex Analysis and Documentation of Historical Buildings Using New Geomatics Methods. The Civil Engineering Journal. 2016, 2016(4), 1-8. ISSN 1805-2576. https://doi.org/10.14311/CEJ.2016.04.0027

Jouan, P., Hallot, P. 2019. DIGITAL TWIN: A HBIM-BASED METHODOLOGY TO SUPPORT PREVENTIVE CONSERVATION OF HISTORIC ASSETS THROUGH HERITAGE SIGNIFICANCE AWARENESS. ISPRS International Archives of the Photogrammetry, Remote Sensing and Spatial Information Sciences. XLII-2/W15. 609-615. 10.5194/isprs-archives-XLII-2-W15-609-2019.

Leica Geosystems, 2022. "Leica BLK360 Imaging Laser Scanner | Leica Geosystems," 2022. [Online]. Available: https://leica-geosystems.com/products/laser-

scanners/scanners/blk360. [Accessed: 06-Jan-2022].

Matoušková,E., Pavelka,K., Smolík, T., Pavelka, jr.,2021. "Earthen Jewish architecture of southern Morocco: Documentation of unfired brick synagogues and mellahs in the drâa-tafilalet region," Appl. Sci., vol. 11, no. 4, pp. 1-25.

Patrucco, G., Rinaudo, F., Spreafico, A. 2019. Multi-Source Approaches for Complex Architecture Documentation: The "Palazzo Ducale" In Gubbio (Perugia, Italy). ISPRS International Archives of the Photogrammetry, Remote Sensing and Spatial Information Sciences. XLII-2/W11. 953-960. https://doi.org/10.5194/isprs-archives-XLII-2-W11-953-2019

Pavelka, K., Ruzicka, S., Bílá, Z. 2013. PHOTO-PLAN CREATION OF CYLINDRICAL OBJECTS. ISPRS Annals of the Photogrammetry, Remote Sensing and Spatial Information Sciences, 229-234. https://www.isprs-ann-photogrammremote-sens-spatial-inf-sci.net/II-5-W1/229/2013/

Pavelka, K., Svatuskova, J., Králová, V. 2007. PHOTOGRAMMETRIC DOCUMENTATION AND VISUALIZATION OF CHOLI MINARET AND GREAT CITADEL IN ERBIL/IRAQ. XXI International CIPA Symposium, 01-06 October 2007, Athens, Greece, https://www.isprs.org/proceedings/XXXVI/5-

C53/papers/FP113.pdf
Pavelka, k., Pappi,C., Pavelka, k., jr., 2021. "Modern possibilities of documentation and replication of archaeological finds," Int. Arch. Photogramm. Remote Sens. Spat. Inf. Sci. ISPRS Arch., vol. 46, no. M-1-2021, pp. 531-538.

Poloprutský, Z. 2019. Building Information Model as a Possibility for Digital Reconstruction of the Buldings of Rural Architecture. In: Measurement, Visualisation and Processing in BIM for Design and Construction Management. International Society of Photogrammetry and Remote Sensing, 2019. p. 5357. vol. XLII-5/W2. ISSN 2194-9034.

Poloprutský, Z. 2019. "Building information model as a possibility for digital reconstruction of the buildings of rural architecture," Int. Arch. Photogramm. Remote Sens. Spat. Inf. Sci. - ISPRS Arch., vol. 42, no. 5/W2, pp. 53-57, 2019.

Poloprutský, Z 2019. "Parametric Modelling for HBIM Design of Window Library for Rural Building"

The Civil Engineering Journal. 2019,(4), 620-630. ISSN 18052576.

Šedina, J.; Housarová, E.; Raeva, P. 2019. Using RPAS for the detection of archaeological objects using multispectral and thermal imaging, European Journal of Remote Sensing. 52(sup1),182-191.

https://doi.org/10.1080/22797254.2018.1562848 